\title{
Liver Transplantation for Hepatocellular Carcinoma
}

\author{
Renumathy Dhanasekaran • Julie K. Heimbach
}

Published online: 25 September 2014

(C) Springer International Publishing AG 2014

\begin{abstract}
Hepatocellular carcinoma (HCC) is the most common primary malignancy of the liver and is associated with very poor overall survival. Most patients present with advanced-stage disease and are therefore not eligible for curative surgical therapies. In patients who do present with earlystage HCC, liver transplantation (LT) is an optimal curative surgical option, if the patient is eligible for LT. Most HCC develops in the background of chronic liver disease, and LT serves as a treatment for both the cancer and the underlying cirrhosis. Although the initial experience with LT for HCC was associated with a high recurrence rate and poor survival, it was later demonstrated that by limiting LT to patients with early-stage disease, excellent long-term survival could be attained. A set of size criteria termed Milan criteria (single tumor $\leq 5 \mathrm{~cm}$ or three or more tumor nodules, each $\leq 3 \mathrm{~cm}$ ) has been established as the size and number cut off associated with the best post-transplant outcome for patients with HCC. Despite strict selection criteria, recurrence of $\mathrm{HCC}$ does occur in $10-15 \%$ of patients. Multiple different locoregional therapies and systemic therapies such as sorafenib are being employed to prevent recurrence in patients with aggressive phenotypes but their efficacy has not been well established.
\end{abstract}

Keywords Liver cancer · Transplantation · Bridging · Allocation $\cdot$ Recurrence $\cdot$ Adjuvant therapy

R. Dhanasekaran

Division of Gastroenterology and Hepatology, Mayo Clinic, Rochester, MN 55905, USA

J. K. Heimbach $(\bowtie)$

Division of Transplantation Surgery, Mayo Clinic, Rochester, MN 55905, USA

e-mail: Heimbach.julie@mayo.edu

\section{Introduction}

Hepatocellular carcinoma (HCC) is a malignancy with poor prognosis and in 2012 it was the second most frequent cause of cancer-related mortality worldwide [1]. The incidence varies by region, with more than $80 \%$ of the cancer burden in Asia and Africa. Although it is a relatively uncommon cancer in the USA, the incidence rate for new liver cancer has reported to be rising at an average of $4.1 \%$ per year over 2002-2011 [2], and the proportion of patients being transplanted for HCC also appears to be rising (Fig. 1). Although the prognosis for HCC remains poor with the overall 5-year survival being less than $20 \%$, the treatment option associated with the best survival outcome is liver transplantation (LT), with a 5-year survival of $65-70 \%$ [3]. Although the safety and feasibility of transplantation for $\mathrm{HCC}$ has been well established, several challenges remain. The optimal criteria for selecting HCC patients for LT are still being debated; the current allocation criteria appear to over-prioritize HCC patients, the role of pre-transplant bridging therapies for HCC is not clear, an ideal immunosuppression regimen in this subgroup has not been established, and the efficacy of adjuvant therapy in preventing post-transplant recurrence is still being explored. In this article, we address the above issues and review existing literature related to LT for HCC.

\section{Eligibility for Transplantation}

LT has long been considered an optimal treatment option for HCC but initial experience was not promising with very high recurrence rates and 5-year survival rates of less than $20 \%$ [4, 5]. Subsequently, a few retrospective studies suggested that earlier stage cancers were associated with a better outcome. However, it was the landmark study by Mazzaferro et al. in 1996 that established LT as a viable treatment option for HCC 


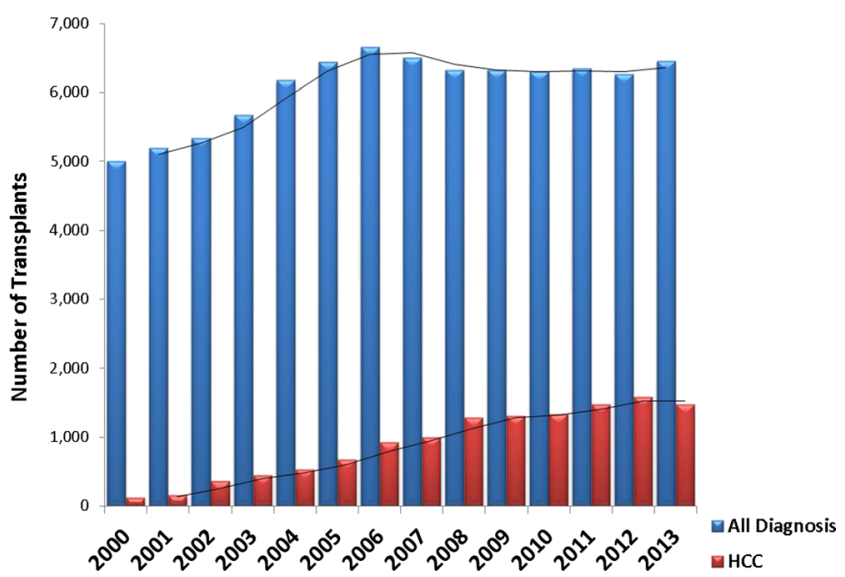

Fig. 1 The number of liver transplantations per year in the USA for all patients (blue) and for those with hepatocellular carcinoma (red)

[6]. They studied 48 patients who underwent deceased donor LT if they satisfied the following criteria: a) single tumor $5 \mathrm{~cm}$ or less in diameter or b) no more than three tumor nodules, each $3 \mathrm{~cm}$ or less in diameter, and c) absence of macrovascular invasion. They reported an excellent 4-year recurrence-free survival rate of $83 \%$. These size restrictions, now known as Milan criteria, have since been widely accepted as optimal selection criteria for LT in patients with HCC.

Some centers have considered these criteria too restrictive and have evaluated expansion of the size cut-off. The University of California in San Francisco (UCSF) proposed the UCSF criteria, which extends transplant eligibility to a single $\mathrm{HCC} \leq 6.5 \mathrm{~cm}$, or up to three lesions, the largest of which is $\leq 4.5 \mathrm{~cm}$ and the cumulative size of the diameters is $\leq 8 \mathrm{~cm}$ [7]. They reported that clinical outcomes of LT for UCSF criteria were comparable to those of patients meeting the Milan criteria [7]. However, these results have not been universally replicable, and a large intention-to-treat analysis of the Organ Procurement and Transplantation Network (OPTN) database reported that survival was significantly decreased in patients who exceeded Milan criteria [8]. Several other criteria have also been proposed as extended criteria for selection of patients with HCC for LT $[9,10]$ (Table 1). However, until further large multicenter trials can confirm the efficacy of extending eligibility criteria, which must be considered in the context of the critical shortage of suitable donor organs, the Milan criteria will likely remain the accepted standard.

\section{Allocation of Donor Organs}

The organ shortage is a major impediment in making LT available to all eligible patients, and because there are not enough organs for all the patients who need them, specific criteria have been formulated to attempt to fairly allocate the limited number of available liver allografts. The current system of organ allocation in the USA uses the Model for End-stage Liver Disease
(MELD) score to allocate liver to the most urgent patient, or "sickest first", as the MELD score is highly predictive of waitlist mortality for patients with decompensated cirrhosis. However, the MELD score is not predictive of short-term mortality in patients with HCC as these patients are more likely to succumb to cancer progression than to the underlying liver disease, though with access to timely transplantation they may have excellent long-term survival. Hence, an assigned MELD exception score has been given to patients with HCC with a tumor burden within Milan criteria, which currently begins at 22 . As long as their tumor remains within Milan criteria, waitlisted patients with a MELD score exception for HCC receive an increase in their assigned score equivalent to a $10 \%$ increase in expected waitlist mortality every 3 months until transplant.

Recent analyses of waitlist survival and drop-out rates have demonstrated that HCC patients have a higher transplant rate and lower wait-list mortality than non-HCC patients, suggesting they are over-prioritized under the current allocation system [11, 12]. In the study by Washburn et al. on patients listed between 2005 and 2008, they found that non-HCC patients had a significantly higher rate of drop-out or death on the waiting list compared with HCC patients $(p<0.001)$ [11]. Another study included around 90,000 patients from the United Network for Organ Sharing (UNOS) database who were listed for liver transplant between 2002 and 2010. They found that patients who received MELD exception points for HCC under current policy (since April 2005) experienced reduced waitlist mortality and enjoyed an increased odds for transplantation compared with non-exception patients with equivalent listing priority [13•]. This over-prioritization of HCC has been recognized by US policy makers and various proposals to adjust the current allocation system are being reviewed with the aim to reduce the disparity in access to transplantation between patients with and without HCC [14].

\section{Evaluation Prior to Listing for Transplantation}

To ensure patients have no evidence of distant metastasis, a thorough pre-transplant evaluation prior to listing for transplant is required [15]. In addition to the standard pre-transplant evaluation, all patients with HCC should have abdominal crosssectional imaging with computed tomography $(\mathrm{CT})$ or magnetic resonance imaging (MRI) of the abdomen to ensure that the tumor size and number are within Milan criteria and also to rule out vascular invasion, metastatic disease, and tumor thrombus in the portal vein. A CT of the chest is performed to rule out lung metastases, and a bone scan is used to rule out skeletal metastasis. A biopsy of the primary tumor is not needed to make the diagnosis of $\mathrm{HCC}$, as long as the characteristic imaging findings are present. The initial UNOS liver allocation policy used relatively vague language and allowed the diagnosis of HCC for lesions, which had a vascular blush corresponding to 
Table 1 Selection criteria for liver transplantation for hepatocellular carcinoma

\begin{tabular}{llll}
\hline Name & Criteria & Advantages & Criticism \\
\hline Milan (6) & $\begin{array}{c}\text { One tumor } \leq 5 \mathrm{~cm} \text { or a maximum } \\
\text { of three tumors each } \leq 3 \mathrm{~cm} \\
\text { No macrovascular invasion }\end{array}$ & $\begin{array}{l}\text { Extensively validated } \\
\text { Considered to be the benchmark } \\
\text { against which other criteria } \\
\text { are measured } \\
\text { Criteria validated in few other studies } \\
\text { UCSF Criteria (7) }\end{array}$ & $\begin{array}{c}\text { One tumor } \leq 6.5 \mathrm{~cm} \text { or a maximum } \\
\text { of three tumor nodules each } \leq 4.5 \mathrm{~cm} \text { in structure to Milan criteria } \\
\text { and a sum of tumor diameters of } \leq 8 \mathrm{~cm} \\
\text { A sum of maximal tumor diameter and } \\
\text { number of tumor nodules } \leq 7\end{array}$ \\
$\begin{array}{c}\text { Any tumor size or number Biopsy } \\
\text { to rule out poorly differentiated HCC } \\
\text { in those beyond Milan criteria }\end{array}$ & $\begin{array}{c}\text { Allows flexibility } \\
\text { reproducible }\end{array}$ & $\begin{array}{c}\text { Takes tumor biology into account } \\
\text { Toronto Criteria (11) }\end{array}$ & $\begin{array}{c}\text { Needs prospective validation } \\
\text { Possible sampling error, risk } \\
\text { for biopsy track seeding }\end{array}$ \\
\hline
\end{tabular}

$H C C$ hepatocellular carcinoma, UCSF University of California San Francisco

the area of suspicion seen on imaging studies. However, a retrospective analysis of UNOS data that compared the pretransplant radiologic stage with the pathologic stage of the explant, found the two to correlate only $44 \%$ of the time [16].

To improve radiologic diagnostic standards for HCC, OPTN recently revised the imaging criteria. Five major issues were addressed in the new policy: (a) minimum technical specifications for hardware for CT scanners and MRI units, (b) dynamic contrast material-enhanced liver imaging protocols, (c) mandatory diagnostic criteria for HCC on images, including the specification that lesions $<1 \mathrm{~cm}$ were indeterminant, (d) reporting requirements using standardized language specific for HCC classification, and (e) requirement for interpretation of images at an OPTN-approved transplantation center [17॰]. Imaging performed for HCC needs to be classified using the OPTN classification. Tumors that fit class $\mathrm{V}$ criteria, which have increased contrast enhancement in the late hepatic arterial phase and washout during later contrast phases, or peripheral rim enhancement (capsule or pseudocapsule), or growth by $50 \%$ or more (on serial CT or MR images obtained $\leq 6$ months apart) will be eligible for MELD exception points. Hypervascular lesions that are between 1 and $2 \mathrm{~cm}$ require washout on delayed-phase imaging and a pseudocapsule, whereas those that are hypervascular and between 2 and $5 \mathrm{~cm}$ require a washout on delayed-phase imaging or a pseudocapsule. The tumor has to be re-imaged every 3 months while the patient is on the waiting list to ensure that the tumor burden remains within Milan criteria.

All patients also undergo extensive blood testing, endoscopies, cardiac assessment, pulmonary evaluation, and ageappropriate cancer screening prior to transplant listing.

\section{Bridging Therapies for Hepatocellular Carcinoma}

The amount of time patients with HCC spend on the transplant list waiting for organ availability varies depending on region.
Based on OPTN data, more than $50 \%$ of patients listed for HCC have waiting times greater than 6 months [3]. Tumor progression has been reported to lead to waiting list drop outs in $10-20 \%$ of patients in various studies $[11,18,19]$. This has led to a consideration for regional therapies for $\mathrm{HCC}$ as a bridge to LT with the intention to prevent tumor progression and maintain eligibility for LT. Options available for bridging include transarterial chemoembolization (TACE), radiofrequency ablation (RFA), percutaneous ethanol injection (PEI), transarterial radioembolization (TARE), and stereotactic body radiotherapy (SBRT). The choice of locoregional therapy (LRT) depends on multiple factors including tumor size, location, multiplicity, patient preference, and individual center experience. Several studies have demonstrated that TACE can help maintain tumors within Milan criteria prior to transplant and can even improve recurrence-free survival [20-22]. TARE, SBRT, and RFA have also been shown to be successful in preventing pre-transplant tumor progression, though data are limited when compared with TACE [23-26]. However, these results have not been uniformly reproducible with multiple other studies reporting no benefit in recurrence rates or posttransplant overall survival [27-29]. Regardless, more than $50 \%$ of the patients with HCC waiting on the transplant list have been shown to have received at least one form of bridging LRT [30]. If bridging LRT is being employed, then the goal should be to achieve complete necrosis of the HCC because the presence of a residual tumor has been associated with a risk for recurrence [31]. Table 2 lists the different LRTs that have been employed as bridging therapies and includes important studies exploring their role [22-24, 26, 32-35].

Sorafenib is an oral multi-kinase inhibitor that has been approved for the treatment of advanced HCC [36, 37]. In a retrospective study of 79 patients who received sorafenib prior to transplant, there was no increased risk for surgical complications with its use [38]. In a recent randomized controlled trial, investigators randomized HCC patients on the transplant waiting list to receive TARE or TARE + sorafenib. They 


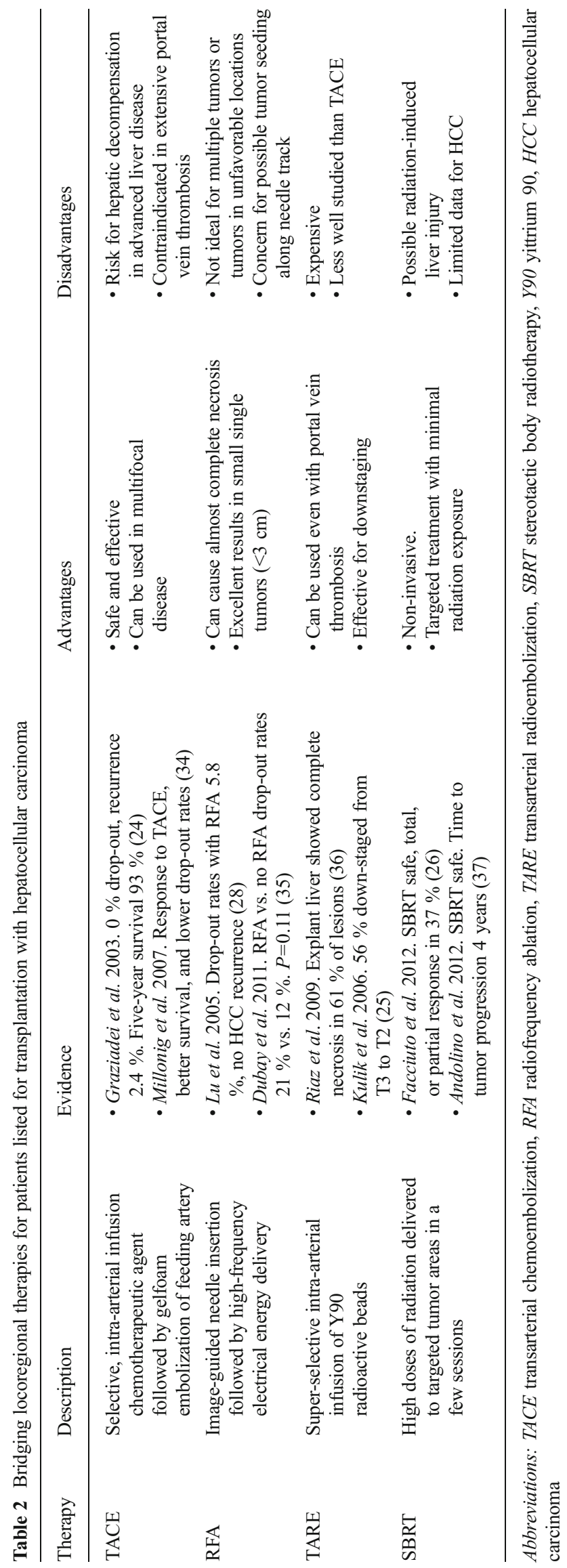

observed that the addition of sorafenib to TARE necessitated dose reductions in all patients and the combination was associated with more peri-transplant biliary complications and was possibly associated with higher rates of acute rejection [39]. The role of sorafenib in pre-transplant patients is currently not clear and the existing data are inconsistent.

To summarize, the decision to consider bridging therapy should be tailored to the individual patient and should be based on tumor characteristics and predicted waiting time on the list for that region. Current consensus guidelines recommend consideration for bridging therapies in patients anticipating a potential wait time longer than 6 months $[40 \bullet, 41]$.

Another role for LRT therapies has been in downsizing tumors beyond Milan criteria to within Milan criteria, thus making patients eligible for transplantation. Several small studies have shown that TACE, TARE, or RFA can be successfully used to downstage large tumors [42-44]. However, there are no randomized controlled trials to confirm these findings and the natural history of these advanced-stage tumors that have been downsized is not well understood. At the present time, the international consensus guidelines do not support downsizing as a standard means to achieve transplant eligibility until more research is conducted to address drop-out rates and 5-year recurrence and survival.

\section{Clinical Outcomes and Prognostic Factors}

If Milan criteria are strictly followed in patient selection, then the post-transplant peri-operative mortality, 1-, and 5-year mortality are expected to be $3 \%,<10 \%$, and $<30 \%$, respectively, in deceased donor liver transplantation (DDLT) [41]. Multiple recipient-related factors such as elevated alphafetoprotein levels [45], advanced tumor grade and stage [46], and presence of vascular invasion [47] have been reported to influence outcome after LT. In a meta-analysis of 90 studies by Mazzaferro et al., they found the Milan criteria to be significant and independent predictors of post-transplant survival [48]. Underlying etiology for liver disease also appears to play an important prognostic role. Hepatitis $\mathrm{C}$ virus (HCV)-related cirrhosis is currently the most common indication for LT. Patients with HCC underlying HCV have been reported to have more advanced tumors and more advanced liver disease at the time of diagnosis of $\mathrm{HCC}$ when compared with hepatitis $B$ virus [49]. As expected, this has been associated with higher recurrence rates and poorer survival in HCV-related HCC. Non-alcoholic steatohepatitis is becoming an increasingly common indication for LT. Wong et al. have recently reported that compared with $\mathrm{HCV}$, patients with NASH had significantly higher post-transplantation survival (hazard ratio 0.69 , $95 \%$ confidence interval $0.63-0.77$ ) and a lower risk of graft failure (HR 0.76, $95 \%$ CI $0.69-0.83$ ) on analysis of UNOS 
data between 2002 and 2014 [50], though whether this holds true for NASH patients with HCC remains to be seen.

Living donor liver transplantation (LDLT) is also an option for patients with HCC. Initially, concerns regarding higher recurrence rates among patients with LDLT were raised [51-53], though examination of explant pathology demonstrated more unfavorable tumor characteristics in LDLT recipients. The shortened waiting time for LDLT recipients may lead to patients with more aggressive phenotypes undergoing LT, rather than experiencing waitlist drop out while waiting for DDLT. As LDLT is more technically demanding than DDLT, initial reports of LDLT for HCC also included patients who were transplanted early in the center's experience with LDLT, and thus within the learning curve. Subsequent studies that have excluded the early cases and carefully controlled for a similar stage of disease have reported comparable survival and recurrence rates between DDLT and LDLT [53, 54]. A meta-analysis of seven studies with a total of 1310 participants was conducted to address the controversy [55•]. They found that LDLT and DDLT were associated with statistically similar patient survival and $\mathrm{HCC}$ recurrence rates.

\section{Immunosuppression}

Patients who undergo LT require lifelong immunosuppression to prevent immunologic graft loss, but patients who had pretransplant HCC are in a unique situation. Higher levels of immunosuppression can potentially contribute to the risk of tumor recurrence and lower levels can lead to graft rejection. In a study by Vivarelli et al., higher serum concentrations of cyclosporine were independently associated with a higher incidence of tumor recurrence and poorer recurrence-free survival [56]. This was also shown to be true by a more recent study from Europe where they demonstrated that higher exposure to tacrolimus or cyclosporine within the first month after LT was associated with a significantly increased risk of HCC recurrence [57]. Hence, the minimum appropriate level of immunosuppression that balances both the risk of rejection and recurrence should be maintained.

Sirolimus is a mammalian target of rapamycin inhibitor that has been suggested to have a potentially beneficial role for immunosuppression in patients with $\mathrm{HCC}$ who are at high risk for recurrence. Guba et al. initially reported in 2002 that sirolimus can inhibit metastatic tumor progression and angiogenesis in mouse models by potentially blocking the vascular endothelial growth factor pathway [58]. A few small studies from single centers appeared to confirm that this phenomenon holds true in clinical settings [59-61]. A recent meta-analysis addressed this question and confirmed that patients with $\mathrm{HCC}$ who received sirolimus immunosuppression experienced lower recurrence rates (odds ratio $(\mathrm{OR})=0.30, p=0.001$ ), lower recurrence-related mortality $(\mathrm{OR}=0.29, p=0.005)$, and also lower overall mortality $(\mathrm{OR}=0.35, p<0.001)$ when compared with those who did not receive sirolimus [62]. However, sirolimus is associated with hepatic artery thrombosis (when used early), poor wound healing, and higher rates of metabolic complications when compared with calcineurin inhibitors. In fact, the US Food and Drug Administration added a black-box warning to sirolimus in 2008 that its use was associated with excess mortality, graft loss, and hepatic artery thrombosis following LT. Current guidelines do not recommend switching patients with HCC to sirolimus for immunosuppression as high-quality data from clinical trials are not yet available.

\section{Recurrence}

Despite stringent pre-transplant selection criteria for $\mathrm{HCC}$, recurrence does occur and it remains a clinical challenge. Ideal intervals for post-transplant surveillance for recurrence are not clear. Broadly, closer surveillance (approximately every 6 months) is recommended in the initial 1-2 years posttransplant and it can be extended to a longer interval afterwards. Recurrence rates depend on pre-transplant inclusion criteria and they vary widely between 5 and $25 \%$ [63-65]. High pre-transplant alpha-fetoprotein, advanced tumor grade, presence of microvascular invasion in the explant, tumor size beyond Milan criteria on explant, and high serum levels of immunosuppressants have been shown to be risk factors for recurrence in different studies [66-70]. However, tumor size and grade alone do not accurately reflect tumor biology and hence efforts are underway to identify gene expression profiles in explant tumors to predict the risk for recurrence. A study by Barry et al. analyzed microRNA expression and identified a biomarker panel that was able to accurately distinguish between patients with and without $\mathrm{HCC}$ recurrence after LT [71]. In their cohort of 64 patients transplanted for $\mathrm{HCC}$, this biomarker was shown to outperform the Milan criteria in identifying patients at risk for recurrence. With further validation of such scores it may be possible to more accurately predict the risk of recurrence.

An important question is if patients at high risk for recurrence of HCC are able to be identified, can they be treated with adjuvant therapy to decrease the risk of recurrence? HCC has been traditionally considered to be resistant to chemotherapy and some studies that examined the role of conventional chemotherapy as adjuvant treatment in high-risk patients did not show improvement in recurrence rates [72, 73]. An animal model study proposed that sorafenib is effective in inhibiting cancer recurrence and metastasis after LT for HCC [74]. Clinical studies are currently underway to hopefully confirm these findings. Preliminary data from a study by Shetty et al. who prospectively evaluated seven patients who received sorafenib adjuvant therapy as they were deemed high risk 
for recurrence (viable tumor beyond Milan criteria on explant) are promising [75]. In this small study, on comparison to historical controls, they reported that the use of sorafenib was associated with lower rates of recurrence. For now, more robust data are needed before recommendations can be made about adjuvant therapy.

Treatment of HCC recurrence in transplant patients is challenging because these patients are on immunosuppression, have altered anatomy, and are at risk for significant drug-drug interactions; however, theoretically all nonsurgical and surgical therapies that are available to pre-transplant patients may be considered. Resection of intrahepatic recurrence or isolated extra-hepatic metastasis is feasible and Valdivieso et al. reported that patients that underwent resection of recurrent disease did have better survival [76]. In this series, only a very small select group of patients were found to be eligible for $\mathrm{R} 0$ resection, and in general, such strategies should be considered palliative rather than curative. TACE is widely employed as a bridging therapy prior to transplantation but its employment in a post-transplant setting is risky given the high propensity for abscess formation and the risk of hepatic artery stenosis/thrombosis. Several small studies have suggested that this is still a safe and feasible treatment, even if the impact on the overall survival does not appear to be profound [77-79]. Sorafenib has been viewed as an attractive systemic therapeutic option for the management of HCC recurrence. Early reports suggest high rates of adverse effects and discontinuation with sorafenib [80,81], and DeSimone et al. recently reported data from a single-center retrospective analysis on LT recipients with unresectable HCC recurrence undergoing combination therapy with everolimus and sorafenib [82]. Of the seven patients in this study, five patients were alive at a median follow-up of 6 months, though four of them with tumor progression. They found that treatment with this combination was challenging as patients had a high incidence of adverse effects. Contrary to most of these above studies, a recent case cohort study of 39 patients with HCC recurrence (best supportive care $n=24$; sorafenib $n=15$ ) reported that sorafenib appeared to be associated with an acceptable safety profile and even survival benefit [83•].

\section{Conclusion}

HCC is a lethal malignancy that develops in the background of chronic liver disease in more than $95 \%$ of cases. LT can provide a curative option that addresses both the cancer and the underlying liver disease. Unfortunately, given the current extreme shortage of donor organs, not all patients who would benefit from LT are able to undergo transplantation. Thus, it is imperative to ensure that recipients of organs do not have unfavorable features that can lead to an increased risk of tumor recurrence or graft failure. Hence, very strict tumor size and number criteria (Milan criteria) have been established to identify patients with $\mathrm{HCC}$ who have an acceptable risk profile for transplantation. Patients who are eligible for LT, because of a prolonged time on the wait list or they face the risk of tumor progression beyond Milan criteria, may be treated with bridging LRT to maintain eligibility for transplantation. This approach is recommended mostly for patients who are expected to stay on the wait list for longer than 6 months. Some centers also treat patients with larger tumors with LRT to downstage tumor size and then list for LT, though it is not yet accepted as a standard of care. Although initial reports suggested that LDLT could be associated with higher recurrence rates, this does not appear to be reflected in more recent data and LDLT remains an excellent treatment option for $\mathrm{HCC}$ in regions with a prolonged waiting time. The minimum appropriate level of immunosuppression should be maintained in HCC patients, and sirolimus and everolimus may have a beneficial role in patients at increased risk of recurrence, though the current data are very limited. Recurrence of HCC after LT occurs in around $10 \%$ of patients and these patients have a poor prognosis.

\section{Compliance with Ethics Guidelines}

Conflict of Interest Dr. Renumathy Dhanasekaran and Dr. Julie K. Heimbach each declare no potential conflict of interest.

Human and Animal Rights and Informed Consent This article does not contain any studies with human or animal subjects performed by any of the authors.

\section{References}

Papers of particular interest, published recently, have been highlighted as:

- Of importance

1. Ferlay JSI, Ervik M, Dikshit R, Eser S, Mathers C, Rebelo M, et al. GLOBOCAN 2012 v1.0, cancer incidence and mortality worldwide: IARC CancerBase No. 11 [Internet]. Lyon: International Agency for Research on Cancer; 2013. Available from: http:// globocan.iarc. fr.

2. SEER cancer statistics factsheets: liver and intrahepatic bile duct cancer. National Cancer Institute. Bethesda MD, http://seer.cancer. gov/statfacts/html/livibd.html. Accessed on Dec 15th, 2013.

3. Based on OPTN data as of April 11.

4. Ringe B, Pichlmayr R, Wittekind C, Tusch G. Surgical treatment of hepatocellular carcinoma: experience with liver resection and transplantation in 198 patients. World J Surg. 1991;15(2):270-85.

5. Penn I. Hepatic transplantation for primary and metastatic cancers of the liver. Surgery. 1991;110(4):726-34. discussion 34-35.

6. Mazzaferro V, Regalia E, Doci R, Andreola S, Pulvirenti A, Bozzetti F, et al. Liver transplantation for the treatment of small hepatocellular carcinomas in patients with cirrhosis. New Engl J Med. 1996;334(11):693-9. 
7. Yao FY, Ferrell L, Bass NM, Watson JJ, Bacchetti P, Venook A, et al. Liver transplantation for hepatocellular carcinoma: expansion of the tumor size limits does not adversely impact survival. Hepatology. 2001;33(6):1394-403.

8. Pelletier SJ, Fu S, Thyagarajan V, Romero-Marrero C, Batheja MJ, Punch JD, et al. An intention-to-treat analysis of liver transplantation for hepatocellular carcinoma using organ procurement transplant network data. Liver Transplant. 2009;15(8):859-68.

9. Mazzaferro V, Llovet JM, Miceli R, Bhoori S, Schiavo M, Mariani $\mathrm{L}$, et al. Predicting survival after liver transplantation in patients with hepatocellular carcinoma beyond the Milan criteria: a retrospective, exploratory analysis. Lancet Oncol. 2009;10(1):35-43.

10. DuBay D, Sandroussi C, Sandhu L, Cleary S, Guba M, Cattral MS, et al. Liver transplantation for advanced hepatocellular carcinoma using poor tumor differentiation on biopsy as an exclusion criterion. Ann Surg. 2011;253(1):166-72. doi:10.1097/SLA.0b013e31820508f1.

11. Washburn K, Edwards E, Harper A, Freeman R. Hepatocellular carcinoma patients are advantaged in the current liver transplant allocation system. Am J Transplant. 2010;10(7):1643-8.

12. Mehta N, Dodge JL, Goel A, Roberts JP, Hirose R, Yao FY. Identification of liver transplant candidates with hepatocellular carcinoma and a very low dropout risk: implications for the current organ allocation policy. Liver Transplant. 2013;19(12):1343-53.

13. Massie AB, Caffo B, Gentry SE, Hall EC, Axelrod DA, Lentine KL, et al. MELD exceptions and rates of waiting list outcomes. Am J Transplant. 2011;11(11):2362-71. This study demonstrates that patients with hepatocellular carcinoma (HCC) are advantaged over patients without HCC in the current allocation system.

14. Pomfret EA, Washburn K, Wald C, Nalesnik MA, Douglas D, Russo M, et al. Report of a national conference on liver allocation in patients with hepatocellular carcinoma in the United States. Liver Transpl. 2010;16(3):262-78. doi:10.1002/1t.21999.

15. http://optn.transplant.hrsa.gov/policiesAndBylaws/policies.asp (Accessed on April 07.

16. Freeman RB, Mithoefer A, Ruthazer R, Nguyen K, Schore A, Harper A, et al. Optimizing staging for hepatocellular carcinoma before liver transplantation: a retrospective analysis of the UNOS/OPTN database. Liver Transplant. 2006;12(10):1504-11.

17. Wald C, Russo MW, Heimbach JK, Hussain HK, Pomfret EA, Bruix J. New OPTN/UNOS policy for liver transplant allocation: standardization of liver imaging, diagnosis, classification, and reporting of hepatocellular carcinoma. Radiology. 2013;266(2): 376-82. This study provides the new imaging criteria for liver allocation in the USA.

18. Majno P, Lencioni R, Mornex F, Girard N, Poon RT, Cherqui D. Is the treatment of hepatocellular carcinoma on the waiting list necessary? Liver Transplant. 2011;17 Suppl 2:S98-108.

19. Llovet JM, Fuster J, Bruix J. Intention-to-treat analysis of surgical treatment for early hepatocellular carcinoma: resection versus transplantation. Hepatology. 1999;30(6):1434-40.

20. Nicolini D, Svegliati-Baroni G, Candelari R, Mincarelli C, Mandolesi A, Bearzi I, et al. Doxorubicin-eluting bead vs conventional transcatheter arterial chemoembolization for hepatocellular carcinoma before liver transplantation. World J Gastroenterol. 2013;19(34):5622-32.

21. Troisi R, Defreyne L, Hesse UJ, Praet M, Decruyenaere J, De Hemptinne B. Multimodal treatment for hepatocellular carcinoma on cirrhosis: the role of chemoembolization and alcoholization before liver transplantation. Clin Transplant. 1998;12(4):313-9.

22. Graziadei IW, Sandmueller H, Waldenberger P, Koenigsrainer A, Nachbaur K, Jaschke W, et al. Chemoembolization followed by liver transplantation for hepatocellular carcinoma impedes tumor progression while on the waiting list and leads to excellent outcome. Liver Transplant. 2003;9(6):557-63.

23. Kulik LM, Atassi B, van Holsbeeck L, Souman T, Lewandowski RJ, Mulcahy MF, et al. Yttrium-90 microspheres (TheraSphere) treatment of unresectable hepatocellular carcinoma: downstaging to resection, RFA and bridge to transplantation. J Surg Oncol. 2006;94(7):572-86.

24. Facciuto ME, Singh MK, Rochon C, Sharma J, Gimenez C, Katta $\mathrm{U}$, et al. Stereotactic body radiation therapy in hepatocellular carcinoma and cirrhosis: evaluation of radiological and pathological response. J Surg Oncol. 2012;105(7):692-8.

25. Tsuchiya K, Asahina Y, Tamaki N, Yasui Y, Hosokawa T, Ueda K, et al. Risk factors for exceeding the Milan criteria after successful radiofrequency ablation in patients with early-stage hepatocellular carcinoma. Liver Transplant. 2014;20(3):291-7.

26. Lu DS, Yu NC, Raman SS, Lassman C, Tong MJ, Britten C, et al. Percutaneous radiofrequency ablation of hepatocellular carcinoma as a bridge to liver transplantation. Hepatology. 2005;41(5):1130-7.

27. Decaens T, Roudot-Thoraval F, Bresson-Hadni S, Meyer C, Gugenheim J, Durand F, et al. Impact of pretransplantation transarterial chemoembolization on survival and recurrence after liver transplantation for hepatocellular carcinoma. Liver Transplant. 2005;11(7):767-75.

28. Porrett PM, Peterman H, Rosen M, Sonnad S, Soulen M, Markmann JF, et al. Lack of benefit of pre-transplant locoregional hepatic therapy for hepatocellular cancer in the current MELD era. Liver Transplant. 2006;12(4):665-73.

29. Cabrera R, Dhanasekaran R, Caridi J, Clark V, Morelli G, Soldevila-Pico C, et al. Impact of transarterial therapy in hepatitis C-related hepatocellular carcinoma on long-term outcomes after liver transplantation. Am J Clin Oncol. 2012;35(4):345-50.

30. Freeman RB, Steffick DE, Guidinger MK, Farmer DG, Berg CL, Merion RM. Liver and intestine transplantation in the United States, 1997-2006. Am J Transplant. 2008;8(4p2):958-76.

31. Ravaioli M, Grazi GL, Ercolani G, Fiorentino M, Cescon M, Golfieri R, et al. Partial necrosis on hepatocellular carcinoma nodules facilitates tumor recurrence after liver transplantation. Transplantation. 2004;78(12):1780-6.

32. Millonig G, Graziadei IW, Freund MC, Jaschke W, Stadlmann S, Ladurner R, et al. Response to preoperative chemoembolization correlates with outcome after liver transplantation in patients with hepatocellular carcinoma. Liver Transplant. 2007;13(2):272-9.

33. DuBay DA, Sandroussi C, Kachura JR, Ho CS, Beecroft JR, Vollmer $\mathrm{CM}$, et al. Radiofrequency ablation of hepatocellular carcinoma as a bridge to liver transplantation. HPB. 2011;13(1):24-32.

34. Riaz A, Kulik L, Lewandowski RJ, Ryu RK, Giakoumis Spear G, Mulcahy MF, et al. Radiologic-pathologic correlation of hepatocellular carcinoma treated with internal radiation using yttrium-90 microspheres. Hepatology. 2009;49(4):1185-93.

35. Andolino DL, Johnson CS, Maluccio M, Kwo P, Tector AJ, Zook J, et al. Stereotactic body radiotherapy for primary hepatocellular carcinoma. Int J Radiat Oncol Biol Phys. 2011;81(4):7.

36. Cheng AL, Kang YK, Chen Z, Tsao CJ, Qin S, Kim JS, et al. Efficacy and safety of sorafenib in patients in the Asia-Pacific region with advanced hepatocellular carcinoma: a phase III randomised, double-blind, placebo-controlled trial. Lancet Oncol. 2009;10(1):25-34.

37. Llovet JM, Ricci S, Mazzaferro V, Hilgard P, Gane E, Blanc JF, et al. Sorafenib in advanced hepatocellular carcinoma. New Engl J Med. 2008;359(4):378-90.

38. Frenette CT, Boktour M, Burroughs SG, Kaseb A, Aloia TA, Galati $\mathrm{J}$, et al. Pre-transplant utilization of sorafenib is not associated with increased complications after liver transplantation. Transplant Int. 2013;26(7):734-9.

39. Kulik L, Vouche M, Koppe S, Lewandowski RJ, Mulcahy MF, Ganger D, et al. Prospective randomized pilot study of Y $90+/$ -sorafenib as bridge to transplantation in hepatocellular carcinoma. J Hepatol. 2014;61(2):309-17.

40. Clavien PA, Lesurtel M, Bossuyt PM, Gores GJ, Langer B, Perrier A. Recommendations for liver transplantation for hepatocellular 
carcinoma: an international consensus conference report. Lancet Oncol. 2012;13(1):e11-22. This study provides a report of a recent international consensus conference on transplantation for hepatocellular carcinoma.

41. EASL-EORTC clinical practice guidelines: management of hepatocellular carcinoma. J Hepatol. 2012;56(4):908-943.

42. Yao FY, Kerlan Jr RK, Hirose R, Davern 3rd TJ, Bass NM, Feng S, et al. Excellent outcome following down-staging of hepatocellular carcinoma prior to liver transplantation: an intention-to-treat analysis. Hepatology. 2008;48(3):819-27.

43. Lewandowski RJ, Kulik LM, Riaz A, Senthilnathan S, Mulcahy MF, Ryu RK, et al. A comparative analysis of transarterial downstaging for hepatocellular carcinoma: chemoembolization versus radioembolization. Am J Transplant. 2009;9(8):1920-8.

44. Gordon-Weeks AN, Snaith A, Petrinic T, Friend PJ, Burls A, Silva MA. Systematic review of outcome of downstaging hepatocellular cancer before liver transplantation in patients outside the Milan criteria. Br J Surg. 2011;98(9):1201-8.

45. Mailey B, Artinyan A, Khalili J, Denitz J, Sanchez-Luege N, Sun CL, et al. Evaluation of absolute serum alpha-fetoprotein levels in liver transplant for hepatocellular cancer. Arch Surg. 2011;146(1):26-33.

46. Iwatsuki S, Dvorchik I, Marsh JW, Madariaga JR, Carr B, Fung JJ, et al. Liver transplantation for hepatocellular carcinoma: a proposal of a prognostic scoring system. J Am Coll Surg. 2000;191(4):389-94.

47. Figueras J, Jaurrieta E, Valls C, Ramos E, Serrano T, Rafecas A, et al. Resection or transplantation for hepatocellular carcinoma in cirrhotic patients: outcomes based on indicated treatment strategy. J Am Coll Surg. 2000;190(5):580-7.

48. Mazzaferro V, Bhoori S, Sposito C, Bongini M, Langer M, Miceli $\mathrm{R}$, et al. Milan criteria in liver transplantation for hepatocellular carcinoma: an evidence-based analysis of 15 years of experience. Liver Transplant. 2011;17(S2):S44-57.

49. Roayaie S, Haim MB, Emre S, Fishbein TM, Sheiner PA, Miller $\mathrm{CM}$, et al. Comparison of surgical outcomes for hepatocellular carcinoma in patients with hepatitis B versus hepatitis C: a Western experience. Ann Surg Oncol. 2000;7(10):764-70.

50. Wong RJ, Chou C, Bonham CA, Concepcion W, Esquivel CO, Ahmed A. Improved survival outcomes in patients with nonalcoholic steatohepatitis and alcoholic liver disease following liver transplantation: an analysis of 2002-2012 United Network for Organ Sharing data. Clin Transplant. 2014;28(6):713-21.

51. Kulik L, Abecassis M. Living donor liver transplantation for hepatocellular carcinoma. Gastroenterology. 2004;127(5 Suppl 1): S277-82.

52. Fisher RA, Kulik LM, Freise CE, Lok AS, Shearon TH, Brown Jr RS, et al. Hepatocellular carcinoma recurrence and death following living and deceased donor liver transplantation. Am J Transplant. 2007;7(6):1601-8

53. Kulik LM, Fisher RA, Rodrigo DR, Brown Jr RS, Freise CE, Shaked A, et al. Outcomes of living and deceased donor liver transplant recipients with hepatocellular carcinoma: results of the A2ALL cohort. Am J Transplant. 2012;12(11):2997-3007.

54. Berg CL, Gillespie BW, Merion RM, Brown Jr RS, Abecassis MM, Trotter JF, et al. Improvement in survival associated with adult-toadult living donor liver transplantation. Gastroenterology. 2007;133(6):1806-13.

55. - Liang W, Wu L, Ling X, Schroder PM, Ju W, Wang D, et al. Living donor liver transplantation versus deceased donor liver transplantation for hepatocellular carcinoma: a meta-analysis. Liver Transplant. 2012;18(10):1226-36. This study establishes that living donor liver transplant provides equivalent outcomes to deceased donor liver liver transplantation for patietns with HCC.

56. Vivarelli M, Cucchetti A, Piscaglia F, La Barba G, Bolondi L, Cavallari A, et al. Analysis of risk factors for tumor recurrence after liver transplantation for hepatocellular carcinoma: key role of immunosuppression. Liver Transplant. 2005;11(5):497-503.
57. Rodriguez-Peralvarez M, Tsochatzis E, Naveas MC, Pieri G, Garcia-Caparros C, O'Beirne J, et al. Reduced exposure to calcineurin inhibitors early after liver transplantation prevents recurrence of hepatocellular carcinoma. J Hepatol. 2013;59(6):1193-9.

58. Guba M, von Breitenbuch P, Steinbauer M, Koehl G, Flegel S, Hornung M, et al. Rapamycin inhibits primary and metastatic tumor growth by antiangiogenesis: involvement of vascular endothelial growth factor. Nat Med. 2002;8(2):128-35.

59. Toso C, Meeberg GA, Bigam DL, Oberholzer J, Shapiro AM, Gutfreund $\mathrm{K}$, et al. De novo sirolimus-based immunosuppression after liver transplantation for hepatocellular carcinoma: long-term outcomes and side effects. Transplantation. 2007;83(9):1162-8.

60. Chinnakotla S, Davis GL, Vasani S, Kim P, Tomiyama K, Sanchez $\mathrm{E}$, et al. Impact of sirolimus on the recurrence of hepatocellular carcinoma after liver transplantation. Liver Transplant. 2009;15(12):1834-42.

61. Kneteman NM, Oberholzer J, Al Saghier M, Meeberg GA, Blitz M, Ma MM, et al. Sirolimus-based immunosuppression for liver transplantation in the presence of extended criteria for hepatocellular carcinoma. Liver Transpl. 2004;10(10):1301-11.

62. Menon KV, Hakeem AR, Heaton ND. Meta-analysis: recurrence and survival following the use of sirolimus in liver transplantation for hepatocellular carcinoma. Aliment Pharmacol Ther. 2013;37(4): 411-9.

63. Escartin A, Sapisochin G, Bilbao I, Vilallonga R, Bueno J, Castells $\mathrm{L}$, et al. Recurrence of hepatocellular carcinoma after liver transplantation. Transplant Proc. 2007;39(7):2308-10.

64. Kornberg A, Kupper B, Tannapfel A, Katenkamp K, Thrum K, Habrecht $\mathrm{O}$, et al. Long-term survival after recurrent hepatocellular carcinoma in liver transplant patients: clinical patterns and outcome variables. Eur J Surg Oncol. 2010;36(3):275-80.

65. Cescon M, Ravaioli M, Grazi GL, Ercolani G, Cucchetti A, Bertuzzo V, et al. Prognostic factors for tumor recurrence after a 12-year, single-center experience of liver transplantations in patients with hepatocellular carcinoma. J Transplant. 2010;904152(10):25.

66. Vivarelli M, Cucchetti A, La Barba G, Ravaioli M, Del Gaudio M, Lauro A, et al. Liver transplantation for hepatocellular carcinoma under calcineurin inhibitors: reassessment of risk factors for tumor recurrence. Ann Surg. 2008;248(5):857-62.

67. Sotiropoulos GC, Molmenti EP, Losch C, Beckebaum S, Broelsch $\mathrm{CE}$, Lang H. Meta-analysis of tumor recurrence after liver transplantation for hepatocellular carcinoma based on 1,198 cases. Eur J Med Res. 2007;12(10):527-34.

68. Dudek K, Kornasiewicz O, Remiszewski P, Kobryn K, ZiarkiewiczWroblewska B, Gornicka B, et al. Impact of tumor characteristic on the outcome of liver transplantation in patients with hepatocellular carcinoma. Transplant Proc. 2009;41(8):3135-7.

69. Lai Q, Avolio AW, Graziadei I, Otto G, Rossi M, Tisone G, et al. Alpha-fetoprotein and modified response evaluation criteria in solid tumors progression after locoregional therapy as predictors of hepatocellular cancer recurrence and death after transplantation. Liver. 2013;19(10):1108-18.

70. Lai Q, Merli M, Ginanni Corradini S, Mennini G, Gentili F, Molinaro A, et al. Predictive factors of recurrence of hepatocellular carcinoma after liver transplantation: a multivariate analysis. Transplant Proc. 2009;41(4):1306-9.

71. Barry CT, D'Souza M, McCall M, Safadjou S, Ryan C, Kashyap R, et al. Micro RNA expression profiles as adjunctive data to assess the risk of hepatocellular carcinoma recurrence after liver transplantation. Am J Transplant. 2012;12(2):428-37.

72. Söderdahl G, Bäckman L, Isoniemi H, Cahlin C, Höckerstedt K, Broomé U, et al. A prospective, randomized, multi-centre trial of systemic adjuvant chemotherapy versus no additional treatment in liver transplantation for hepatocellular carcinoma. Transplant Int. 2006;19(4):288-94 
73. Bernal E, Montero JL, Delgado M, Fraga E, Costan G, Barrera P, et al. Adjuvant chemotherapy for prevention of recurrence of invasive hepatocellular carcinoma after orthotopic liver transplantation. Transplant Proc. 2006;38(8):2495-8.

74. Yan J, Tan C, Gu F, Jiang J, Xu M, Huang X, et al. Sorafenib delays recurrence and metastasis after liver transplantation in a rat model of hepatocellular carcinoma with high expression of phosphorylated extracellular signal-regulated kinase. Liver Transplant. 2013;19(5): 507-20.

75. Shetty K, Dash C, Laurin J. Use of adjuvant sorafenib in liver transplant recipients with high-risk hepatocellular carcinoma. J Transplant. 2014;2014:5.

76. Valdivieso A, Bustamante J, Gastaca M, Uriarte JG, Ventoso A, Ruiz P, et al. Management of hepatocellular carcinoma recurrence after liver transplantation. Transplant Proc. 2010;42(2):660-2.

77. Ko HK, Ko GY, Yoon HK, Sung KB. Tumor response to transcatheter arterial chemoembolization in recurrent hepatocellular carcinoma after living donor liver transplantation. Korean J Radiol. 2007;8(4):320-7.

78. Zhou B, Shan H, Zhu KS, Jiang ZB, Guan SH, Meng XC, et al, Chemoembolization with lobaplatin mixed with iodized oil for unresectable recurrent hepatocellular carcinoma after orthotopic liver transplantation. J Vasc Interv Radiol. 2010;21(3):333-8.

79. Carr BI. Hepatic artery chemoembolization for hepatocellular carcinoma recurrence confined to the transplanted liver. Case Rep Oncol. 2012;5(3):506-10.

80. Zavaglia C, Airoldi A, Mancuso A, Vangeli M, Vigano R, Cordone $\mathrm{G}$, et al. Adverse events affect sorafenib efficacy in patients with recurrent hepatocellular carcinoma after liver transplantation: experience at a single center and review of the literature. Eur $\mathrm{J}$ Gastroenterol Hepatol. 2013;25(2):180-6.

81. Staufer K, Fischer L, Seegers B, Vettorazzi E, Nashan B, Sterneck M. High toxicity of sorafenib for recurrent hepatocellular carcinoma after liver transplantation. Transplant Int. 2012;25(11):1158-64.

82. De Simone P, Crocetti L, Pezzati D, Bargellini I, Ghinolfi D, Carrai $\mathrm{P}$, et al. Efficacy and safety of combination therapy with everolimus and sorafenib for recurrence of hepatocellular carcinoma after liver transplantation. Transplant Proc. 2014;46(1):241-4.

83. Sposito C, Mariani L, Germini A, Flores Reyes M, Bongini M, Grossi G, et al. Comparative efficacy of sorafenib versus best supportive care in recurrent hepatocellular carcinoma after liver transplantation: a case-control study. J Hepatol. 2013;59(1):59-66. This study describes the use of sorafinib post-liver transplant. 